\title{
Reflections On The Theory Of Communication
}

\author{
Jola Bojaxhi \\ Polytechnic University of Tirana \\ Faculty of Mathematics Engineering and \\ Physics Engineering, Center of Foreign Language \\ Fatmir Vrapi \\ Polytechnic University of Tirana \\ Faculty of Mathematics Engineering and \\ Physics Engineering, Center of Foreign Language \\ Edita Stojani \\ Polytechnic University of Tirana \\ Faculty of Mathematics Engineering and \\ Physics Engineering, Center of Foreign Language
}

\begin{abstract}
From its very nature, language is dynamic. From the beginning of speech communication, language was shaped by different factors such as geographical populations movements, social and economic factors, political factors as well as development of technology that has influenced the spread and exchange of ideas. The aim of this paper is, to show how the language has evolved as well as how it has influenced communication between cultures. The methodology is descriptive by looking at different theories of communication. Nowdays, the fast development of technology is making a huge impact on the away we communicate with each other.
\end{abstract}

Keywords: comunication, technology, culture, ideas, language

\section{THEORY OF HUMAN COMMUNICATION}

From its very nature, language is dynamic. From the beginning of speech communication, language was shaped by different factors such as geographical populations movements, social and economic factors, political factors as well as development of technology that has influenced the spread and exchange of ideas.

Defining the term "communication" is not easy. Theodore Clevenger Jr. ${ }^{1}$ noted that "the constant problem of defining communication for scientific or research purposes, stems from the fact the verb "communicate" is well defined in the general dictionary and therefore it is not easy to define in the scientific terms. In fact, it is one of the most elaborated terms of the english language. Researchers have tried to determine the term "communication" but it has not been possible to determine a single definition.

Communication has been systematically studied since the times of antiquity, but became an especially important topic during the 20th century. W. Barnett Pearce ${ }^{2}$ describes this development as " a revolutionary discovery", partly caused by using communication

${ }^{1}$ Clevenger,Jr Th., 1991 “Can one not Communicate? A Conflict of Models" Communication Studies

2 W. Barnett P., 1989, "Communication and the human condition" 
technology such as radio, tv, telephone, satellite as well as computer networks and industrialisation and global policies.

\section{Various theories of human communication}

Communication studies developed considerably during the second part of the 20th century for practical reasons, to help understand what communication can achieve.

In the beginnig, university studies related to communication could take place in different departments such as social studies, arts, mathematics, literature, biology, business and political studies. In fact communication is still studied everywhere in university programs. For example psychologists, study communication as a particular behaviour motivated by various psychological processes. Sociologists focus on society and social processes and that is why they view communication as one of the most important social factors in society. Anthropologists are mainly interested in culture by treating communication as a factor that helps in developing, preserving and changing the culture. There has been considerable collaboration between communication and other fields :"while many branches have benefitted by acquiring a communication model, it is important to acknowledge the fact that these fields have contributed in understanding human communication".

However, other special departments of speech, of communication as well as massmedia communication were developed. In our days, most of these departments are referred to as communication departments or communication studies, but regardless of their name, their common focus is communication as the core of human existence. In contrast with researchers of other fields such as in psychology, sociology, anthropology or business, where communication is considered a secondary process, something inportant for relaying information but only after every other structure has taken its place, researchers in communication field, consider communication as the core element of human life.

The development of communication has various forms in different parts of the world. For example, the theory of communication has different stories in Europe, Asia, Africa or The United States. In The United States, researchers in the beginning studied quantitative communication, trying to prove communication as a social science. Even though, these researchers didn't agree on that aspect, quantitative methods were the standards for many years. On the other hand, the European point of view in communication, was influenced by the Marxist perspective and developed a dependancy on cultural and critical methods. However, in the framework of contemporary study of commmunication, there is significant interaction on both sides.

Communication researchers are also dealing with changes in communication in the West as well as other forms of communication theory. Theories in the East have a tendency to focus on the general, while in the West tend to deal with the study of the part, without worrying about integrating or unifying the whole. In addition, most of the theories in the West are dominated by a individuality vision; people are considered cautious in achieving their personal goals. On the other hand, most of the theories in the East, have a tendency to see communication as a result of unplanned events or consequences.

The views on communication in the East and in the West differ because of the language as well. In the East, the role of oral symbols, especially the talking, is minimized and even seen with skepticim. The way of Western thinking, which values rationality and logic is seen with distrust in eastern traditions. What is appreciated in many Asian philosophies, is intuitive knowledge gained by direct experience. Such knowledge can be gained by not interfering with natural 
events, which explains why silence is so important in communication in the East. Even relations are seen differently in both traditions. In the West, the relation is between two or more people. In many Eastern traditions, relations are more complicated and develop based on changes or social positions, status or power.

Some scholars seek to develop new theories that are specific to a particular culture or region. The work of Molefi Asante on Afrocentricity and the effort of Yoshitaka Miike to describe the theory of communication on Asiacentric ${ }^{3}$, are only two such examples. Underlining theoretical concepts, research materials and methods from this point of view, researchers like Miike and Asante, seek to present alternatives in the field of Eurocentric communication.

However, as any kind of change, cultural change, racial or regional changes in communication theories, should be carefully considered. While the general changes should be taken into cosideration, it is very important to underline that similarities are very large. We can use the above mentioned features of the Eastern mentality to show how each of them manifests itself in Western mentality and vice versa. And no member of the same cultural group does not communicate alike, regardless of the fact that they have common environment. Communication is so wide that can not be confined within a single model.

In an article, Robert T. Craig ${ }^{4}$ proposes a new vision on the theory of communication, which adresses the complexity of the issue. Craig points out that communication can not be combined in a single theory or in a group of theories. Theories will always reflect the diversity of practical ideas on communication in every day life, and that is why we will always have to deal with many approaches. Our goal is not and can not be to set a standard model which can be applied in any communication situation. If such a thing were to happen, communication would turn in a "static field or a dead field".

\section{Characteristics of human communication in modern times}

How has technology changed media communication? For example, personal computer, quick information search and vast possibilities, affects the communication of the modern individual. According to Saffo (1992), when technology comes to the scene, the slowness of the change has to do more with the order than with the expection. He has expressed the 30 year hypothesis, so the amount of time needed for the new ideas to penetrate fully within a certain culture. Most of the ideas require much more time than is predicted in reality. According to him, during the first decade much enthusiasm is expressed as well as hesitation, during the second decade parallel flux appears until the product starts to penetrate in society. The third decade considers the new technology a basic owned by everyone. He takes as an example the first personal computer in the early 1970', named Alto, which the market experts decided not to launch. In the 1980s there was confusion and commercial activity losses, as well as fluctuations in the market. Meanwhile in the 1990s, the computer triumphed with the internet, videogames etc.

... Saffo ${ }^{5}$ reveals some elements that affect the process of incorporating innovations withing a society. According to him, characteristics of an innovation, perception by members of a society, determines the speed of adaptation. He defines these elements: 1 . Relative advantage ( for example: cell phone can be used everywhere), 2. Compliance (cell phone matches the services

\footnotetext{
${ }^{3}$ Molefi Kete Asante, 2003, "Afrocentricity- The theory of social change"

4 Robert T. C. 1999 "Communication theory as a field"

5 Saffo P. 1992 "Design World”
} 
of the standard network system of the network). 3. Multilateral (now cell phones offer games, internet, dictionary and many other services). 4. Reliability (concerns due to piracy should be minimized) 5. Monitoring ( people can easily see and be informed about this technology).

Saffo is a strategist with more than two decades of experience, exploring technological development and its consequences in society. He is the leader of the Scientific Board of Samsung, member of the Council of Science, Technology and Society in the university of Stanford where he teaches. In the late 1990s, World Economic Forum where Paul Saffo was an advisor, named him one of the "100 global leaders of the future".

In the article "Goodbye information, it is time of the Media" (2005), Saffo talks about new forms of exploring the cyberspace. According to him, the era of personal media is emerging, which unlike the traditional media, enables the individual to enhance his sense of creativity, and he describes this comparison as follows:

\begin{tabular}{|l|l|l|}
\hline & Mass media & Personal Media \\
\hline Dominant media & TV & web \\
\hline Place & Living room & Everywhere \\
\hline Experience & See and consume & Take part and create \\
\hline participants & Adults and few in number & Young people and many \\
\hline Business model & Output, service & $\begin{array}{l}\text { Advance payment and a lot } \\
\text { more }\end{array}$ \\
\hline
\end{tabular}

The essence of personal media comes from the deep desire of each of us to be heard, and that is why new ways of group discussion are emerging. Personal media are not only personal but also intimate. But, there is also the dark side of the personal media: while in the mass media society provides similar content for the entire society, and thus giving people the sense of belonging, in today's actuality, individuals choose from the virtual media, exclusive content that matches their view. They isolate themselfs from everything that conflicts with their views. While the traditional mass media was a force pulling the society and keeping it together, personal media has the opposite effect of detaching from the center. We may risk transforming into groups defined by common prejudice and easily disconnected from reality. There is no compensatory power that will attract towards a social gravitational center.

Many writers, scholars and researchers criticise the allege deviation of the language that comes as a result of social media, texts and other forms of digital communication.

In the beginning of 21th century, the possibilities of communication have been increased like never before in the history of human kind. What 20 years ago seemed good material for science fiction, now is reality. Human communication has radically changed and is developing at great speed. For example, when you buy a cell phone and in couple of days it is already history since the market offers you another new model which is much better and half the price. The possibilities of human communication have increased compared to 100 years ago. And yet never before in the history of mankind, the number of divorces, the number of suicides, the number of people using antidepresants has been so high, and never before there has been lack of communication between people.

The continous usage of technology puts us in a completely hypothetical reality. This comes as a result of being constantly connected with the information technology. 
Here lies the contradiction of human evolution. Our capacity to simulate, makes us smarter but less aware, which affects our communication with the environment that surrounds us. This gets worse by the use of technology. We see more people texting, talking on the phone or listening to headphones while walking, a complete disconnection from the surrounding environment or even from oneself. This disconnection is increased with the use of computer.

Everything in the computer is simulation. Our communication with a standard computer is limited in two actions: pressing the buttons on the keyboard and moving the mouse. There is no physical movement only imitation. In this case, the computer uses metaphorically the names of physical objects such as folders, windows,tabs etc. The problem lies in the fact that, the day will come when new computer users will not have seen a real folder. Then how will they understand the folder metaphor used in the computer?

Since our interaction with information technology limits our real, physical and more conscientious communication with other objects throughout the day, the metaphors IT uses to ease its actions will be lost. This is a problem that researchers of human-computer interaction will have to overcome. While computers, mobile phones and other similar devices enable us to be present in any part of the world at any given time, they actually limit us the possibility of perceiving where we are at the moment. If we compare it with the past, it is even more difficult to be aware now than before, but perhaps it is even more necessary than ever.

\section{BIBLIOGRAPHY}

Craig R.T., 1999 “Communication Theory as a Field”, Journal of Communication

Clevenger,Jr Th., 1991, “Can one not Communicate? A Conflict of Models” Communication Studies

Craig R.T., 1993 "Why are there so many Communication Theories?"

Saffo P. 1992 "Design World"

Molefi Kete Asante, 2003, "Afrocentricity- The theory of social change”, African American Images 